\title{
Can Prenatal Methamphetamine Exposure be Considered a Good Animal Model for ADHD?
}

\author{
Anna OCHOZKOVÁ ${ }^{1}$, Lýdia MIHALČÍKOVÁ ${ }^{1}$, Anna YAMAMOTOVÁ ${ }^{1}$, Romana \\ ŠLAMBEROVÁ ${ }^{1}$
}

${ }^{1}$ Department of Physiology, Third Faculty of Medicine, Charles University, Prague, Czech Republic

Received April 18, 2021

Accepted October 11, 2021

\section{Summary}

Attention-deficit/hyperactivity disorder (ADHD) is a mental disorder with a heterogeneous origin with a global incidence that continues to grow. Its causes and pathophysiological mechanisms are not fully understood. It includes a combination of persistent symptoms such as difficulty in concentration, hyperactivity and impulsive behavior. Maternal methamphetamine (MA) abuse is a serious problem worldwide, it can lead to behavioral changes in their offspring that have similarities with behavioral changes seen in children with ADHD. There are several types of ADHD animal models, e.g. genetic models, pharmacologically, chemically and exogenously induced models. One of the exogenously induced ADHD models is the hypoxia-induced model. Our studies, as well as those of others, have demonstrated that maternal MA exposure can lead to abnormalities in the placenta and umbilical cord that result in prenatal hypoxia as well as fetal malnutrition that can result in irreversible changes to experimental animals. Therefore, the aim the present study was to compare the cognitive impairments in MA exposure model with those in established model of ADHD prenatal hypoxia model, to test whether MA exposure is a valid model of ADHD. Pregnant Wistar rats were divided into four groups based on their gestational exposure to MA: (1) daily subcutaneous injections of MA ( $5 \mathrm{mg} / \mathrm{kg}),(2)$ saline injections at the same time and volume, (3) daily 1-hr hypoxia $\left(10 \% \mathrm{O}_{2}\right)$, and (4) no gestational exposure (controls). Male rat offspring were tested for short-term memory in the Novel Object Recognition Test and the Object Location Test between postnatal days 35 and 40. Also their locomotor activity in both tests was measured. Based on the present results, it seems that prenatal MA exposure is not the best animal model for ADHD since it shows corresponding symptoms only in certain measures. Given our previous results supporting our hypothesis, more experiments are needed to further test possible use of prenatal MA exposure as an animal model of the ADHD.

\section{Key words}

Methamphetamine - Hypoxia - ADHD - Prenatal exposure • Memory • OLT • NORT • Hypoxia

\section{Corresponding author}

R. Slamberova, Department of Physiology, Third Faculty of Medicine, Charles University, Ke Karlovu 4, 12000 Prague, Czech Republic. E-mail: romana.slamberova@lf3.cuni.cz

\section{Introduction}

Attention deficit/hyperactivity disorder (ADHD) is the most commonly diagnosed psychiatric disorder in children. ADHD includes a combination of persistent problems, such as difficulty maintaining attention, hyperactivity, and impulsive behavior. Children with ADHD are characterized by low self-esteem, difficult relationships, and poor performance in school (Sagvolden et al. 2005, Russell et al. 2005). The causes and pathophysiological mechanisms of ADHD are not fully understood.

There are several experimental animal models used to study ADHD. Several mouse and rat strains exhibit hyperactivity. But hyperactivity alone is insufficient to qualify rat model of ADHD. It is important to consider other behavioral characteristics (inattentiveness and hyperactivity-impulsivity) and all the complexities of the disorder under experimental conditions (Sagvolden et al. 2011). Genetic models are based on our understanding of the monoaminergic 
systems, in particular the dopaminergic systems, which seem to be the most functionally affected in ADHD (Russell et al. 2007). As such, genetic animal models of ADHD use DAT (dopamine transporter) knock-out mice, SNAP-25 (synaptosomal-associated protein) mutant mice, SHR (Spontaneously hypertensive rat), or NHE $\left(\mathrm{Na}^{+} / \mathrm{H}^{+}\right.$exchanger) mutant mice. SHR appears especially useful in that it displays many of the major symptoms of ADHD (i.e. inattention, hyperactivity, and impulsivity) (Sagvolden et al. 2011).

Other ADHD models are based on pharmacological changes induced, for example, by prenatal ethanol exposure, which can also affect dopaminergic transmission and causes hyperactivity (Gibson et al. 2000, Gilbertson et al. 2005). Similarly, prenatal nicotine exposure can also increase dopamine reuptake in the frontal cortex and affect the fetal oxygen supply (Bush et al. 2000, Knopik 2009, Knopik 2010, Zhu et al. 2014). Both prenatal alcohol and prenatal nicotine exposure have been used as animal models for ADHD (Russel 2007, Tiesler et al. 2014, Atalar et al. 2016).

The last groups of ADHD animal models involve damage to the central nervous system during the early stages of development. Early neonatal hypoxia (postnatal day 1-3) causes ADHD-like hyperactivity in rats (Oorschot et al. 2007). Prenatal ischemia was also shown to induce motor hyperactivity, and short- and long-term memory impairment in adult offspring (Delcour et al. 2012).

Prenatal ischemia-hypoxia or insufficient nutrients and oxygen in the developing fetus is a primary factor leading to lower birth weights (Hendriksen et al. 2002). It influences fetal growth and may lead to a variety of developmental, behavioral, and neurological abnormalities (Kwiatkowski et al. 2014). It may cause changes in the excitability of cortical neurons (Marešová et al. 2001). Prenatal hypoxia has been implicated in numerous neurodevelopmental disorders, including ADHD. Hypoxia, which can be caused by birth asphyxia, respiratory distress syndrome, and preeclampsia, has been independently associated with ADHD (Getahun et al. 2013). Prenatal hypoxia also affects the function of hippocampal neurons (Vetrovoy et al. 2021), which play a role in memory functions responsible for motor development (Sab et al. 2013). Apoptosis of hippocampal neurons, linked to hypoxia, also cause delays in the development of motor reflexes (Golan et al. 2006). Abnormalities in hippocampus, thalamus and striatum were observed after prenatal hypoxia exposure (Robinson et al. 2018). Additionally, prenatal hypoxia has been found to cause memory impairment (Sab et al. 2013, Wei et al. 2016, Zhuravin et al. 2019).

MA is a psychostimulant drug with hallucinogenic effect. The mechanism of action results from acute increases of serotonin and dopamine levels. MA is also described to cause neuronal damage (apoptosis in striatum and prefrontal cortex, long-term damage to dopaminergic and serotonergic axon terminals in hippocampus, striatum and prefrontal cortex) (Zhu et al. 2006, Wagner et al. 1980), excitotoxicity through excessive glutamate release or oxidative stress by increasing nitric oxide synthase activity. (Halpin et al. 2014). Maternal MA exposure can lead to placenta and umbilical cord abnormalities (Vavř́nková et al. 2001) that can result in prenatal hypoxia as well as fetal malnutrition, resulting in irreversible changes. Maternal MA abuse, which is a serious problem worldwide, can lead to changes in offspring behavior very similar to that seen in children with ADHD, e.g. hyperactivity (increased locomotion on behavioral tests) linked to increased dopamine levels, and learning and memory impairment that corresponds with changes in the glutamatergic system of the hippocampus (BubeníkováValešová et al. 2009, Fujáková-Lipsky et al. 2017, Šlamberová et al. 2014, Ochozková et al. 2019). Prenatal MA exposure has also been shown to affect stress responses in adult animals (Holubová et al. 2016). Other studies have shown that prenatal MA exposure impairs postnatal development (Acuff-Smith et al. 1996, Šlamberová et al. 2006) that can lead to lower birth weight (Šlamberová 2012), which is also a risk factor of ADHD (Asherson 2012). Prenatal MA exposure has been shown to lead to morphological brain changes as well as changes in brain metabolism (Abar et al. 2014, AcuffSmith et al. 1996).

Based on the above, the aim of the present study was to test prenatal MA exposure as a potential novel model of ADHD in comparison with prenatal hypoxia exposure. The following behavioral tests were used: The Novel Object Recognition Test (NORT), which measures the exploratory behavior in exploring two different objects-novel vs. familiar (exploratory behavior is a measure of recognition memory), and the Object Location Test (OLT), which measures the exploration of two identical objects, but one is placed to a novel location; this task mainly assesses spatial memory and discrimination (Ennaceur et al. 1997). 


\section{Methods}

The procedures used in this study were reviewed and approved by the Institutional Animal Care and Use Committee and were conducted using the Czech Government Requirements regarding Policies for Humans Care of Laboratory Animals (No. 86/609/EEC) and in compliance with subsequent regulations from the Ministry of Agriculture of the Czech Republic.

\section{Animal groups}

Adult female (250-300 g) Albino Wistar rats were purchased from Velaz (Prague, Czech Republic, bred by Charles River Laboratories International, Inc.) and housed with 4-5 animals per cage in a temperaturecontrolled $\left(22-24{ }^{\circ} \mathrm{C}\right)$ colony room with a standard $12 \mathrm{~h}$ light/dark cycle (lights on at $06.00 \mathrm{~h}$ ). Prior to testing, animals were left undisturbed for one week with food and water ad libitum. After the acclimatization period, the females were weighed and smeared (vaginal lavage) to determine their phase of the estrous cycle. At the onset of the estrous phase of the estrous cycle, females were housed overnight with adult males. One female was paired with one male in a cage overnight. The following day, females were smeared again to check for the presence of sperm and were returned to their previous home cages. The day after impregnation was counted as day 1 of gestation.

Pregnant Wistar rats were divided into four groups. One group was given daily subcutaneous injections of MA $(5 \mathrm{mg} / \mathrm{kg})$ for their entire gestational period. The second group received daily saline injections at the same time and with the same volume. The third group was exposed to $1-\mathrm{hr}$ of hypoxia $\left(10 \% \mathrm{O}_{2}\right)$ daily. The fourth without any gestational interventions was used as a control.

Physiological solution $(0.9 \% \quad \mathrm{NaCl})$ and d-Methamphetamine hydrochloride were purchased from Sigma-Aldrich (Czech Republic).

For hypoxia exposure, rats were placed in a normobaric chamber, which was alternately flushed with $\mathrm{N}_{2}$ to lower the $\mathrm{O}_{2}$ concentration to $10 \%$ (hypoxic phase) followed by reintroduction of a normoxia gas mixture (i.e. reoxygenation phase). The hypoxic phase and the reoxygenation phase lasted $30 \mathrm{~s}$. Rats were exposed to a daily $1 \mathrm{~h}$ reduction of oxygen concentration for three weeks of the gestation period. The chambers were made of Plexiglas $(28 \mathrm{~cm}$ in length, $10 \mathrm{~cm}$ in diameter, with a volume of 2.41 ). A dampening device at the intake end of the chamber was used to dissipate the air stream so that no direct gas jets disturbed the animals.

On day 21 of gestation, females were placed individually in maternity cages (one female per cage). The days of birth were counted as postnatal day (PD) 0 . Mothers and offspring were left undisturbed until the day of testing.

A total of nine litters were used in the experiment. The number of pups in each litter was adjusted to twelve. Eight or nine male and four or three female pups were kept in each litter. In total, 75 male rats were used in this study ( $n=9-10 /$ group and test). We used animals from different litters to prevent the litter bias. The rest of the animals were used in different experiments that are not all a part of this paper. On PD 21 , pups were moved to their own cages, where they were housed in groups of 4 until the NORT (35-38 PD) for and OLT (40-43 PD) tests could be performed.

\section{Behavioral experiments}

\section{NORT}

The Novel Object Recognition test (NORT) was conducted on PD 35-39. The same method was used as described in our previous experiments (Fialová et al. 2015). The NORT consists of three parts: habituation, training, and testing.

Habituation: Animals were habituated to an empty square plastic arena $(45 \times 45 \times 50 \mathrm{~cm})$ for $10 \mathrm{~min}$ a day for three days.

Training: On the fourth day, the animal was trained by placing two identical objects in the arena. The animals explored these objects for $5 \mathrm{~min}$. After $5 \mathrm{~min}$, the animals were returned to their home cages. The testing box and the objects were cleaned of potential odors (using $60 \%$ ethanol) between single animals. Than the animals were tested in the testing phase.

Testing: on the fourth day, rats were placed individually in the plastic dark brown arena, where one of the original objects and one new object of similar size (we used glass jar and metal tin of different shape and different height) were placed in the same locations used during the training phase. The time spent exploring both objects (i.e. the familiar object and the new object) was measured automatically by Ethovision XT7 (Noldus, Netherlands). The calculation of the interest in a new object in the testing phase, which is called the Investigation Ratio (IR), was calculated as the ratio of time spent exploring the new object $\left(\mathrm{T}_{\text {new }}\right)$ divided by the total time spent exploring both objects $\left(\mathrm{T}_{\text {total }}\right)$ $\left(\mathrm{IR}=\mathrm{T}_{\text {new }} / \mathrm{T}_{\text {total }}\right)$. 
$O L T$

Different group of animals was used in the Object Location Test (OLT), that was conducted on PD 40-43. The OLT works on the same rules as NORT and contains the same three parts (habituation, training, and testing); additionally, the calculations are identical $\left(\mathrm{IR}=\mathrm{T}_{\text {new }} / \mathrm{T}_{\text {total }}\right)$. The difference is that OLT measures the exploration time for two identical objects, but one is placed in a novel location. It assesses spatial memory and spatial discrimination (Ennaceur et al. 1997).

Both NORT and OLT were performed in dark room illuminated with red light.

\section{Statistical analysis}

Time spent with objects, velocity, and distance traveled were measured automatically with an Ethovision XT7 (Noldus, Netherlands). The Investigation Ratio $\left(\mathrm{IR}=\mathrm{T}_{\text {new }} / \mathrm{T}_{\text {total }}\right)$ of the testing phase was analyzed using a one-way ANOVA in NORT and OLT separately. Differences were considered significant if $\mathrm{p} \leq 0.05$.

\section{Results}

As shown in Figure 1, group differences were not statistically significant.

As shown in Figure 2, there was a significant effect between groups in terms of distance traveled, NORT $\left[\mathrm{F}_{(3,35)}=9.286, \mathrm{p}<0.01\right]$. Animals prenatally exposed to hypoxia walked longer distances relative to saline and MA group. Animals prenatally exposed to saline walked longer distance relative to control group. There were also significant differences between groups $\left[\mathrm{F}_{(3,35)}=7.331\right.$, $\mathrm{p}<0.01]$ in the velocity in the NORT. Animals exposed prenatally to hypoxia walked faster in than animals from the saline as well as the MA groups. There were no differences between the investigation ratios for the group.

In the OLT, there were significant differences between groups $\left[\mathrm{F}_{(3,32)}=4.638, \mathrm{p}<0.01\right]$ relative in distance traveled. Prenatal MA and hypoxia groups traveled longer distances than control rats. The IR differences between groups approached significance $(p=0.07)$ but did not achieve it.
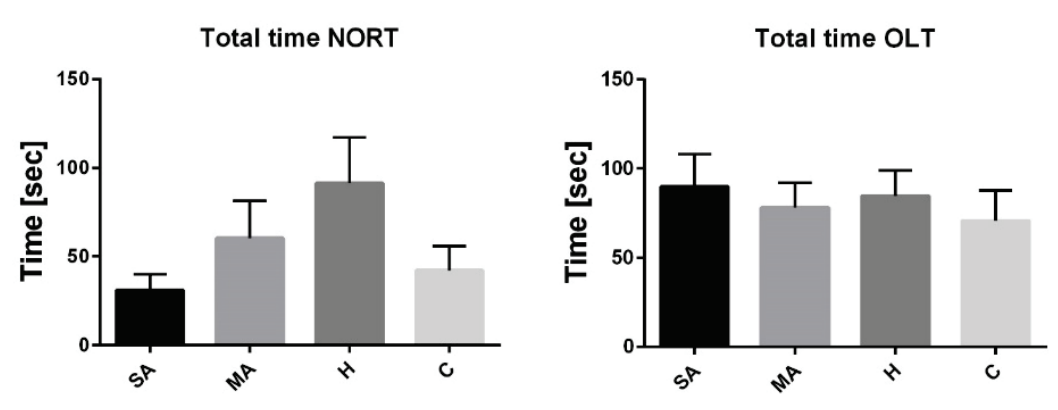

Fig. 1. The effect of prenatal $M A, S A$, Hypoxia, and Control on behavior in the NORT and OLT test. $\mathrm{MA}=$ methamphetamine; $\mathrm{SA}=$ saline; $\mathrm{H}=$ hypoxia; $\mathrm{C}=$ control. Values are mean $\pm \operatorname{SEM}(n=9-10)$.
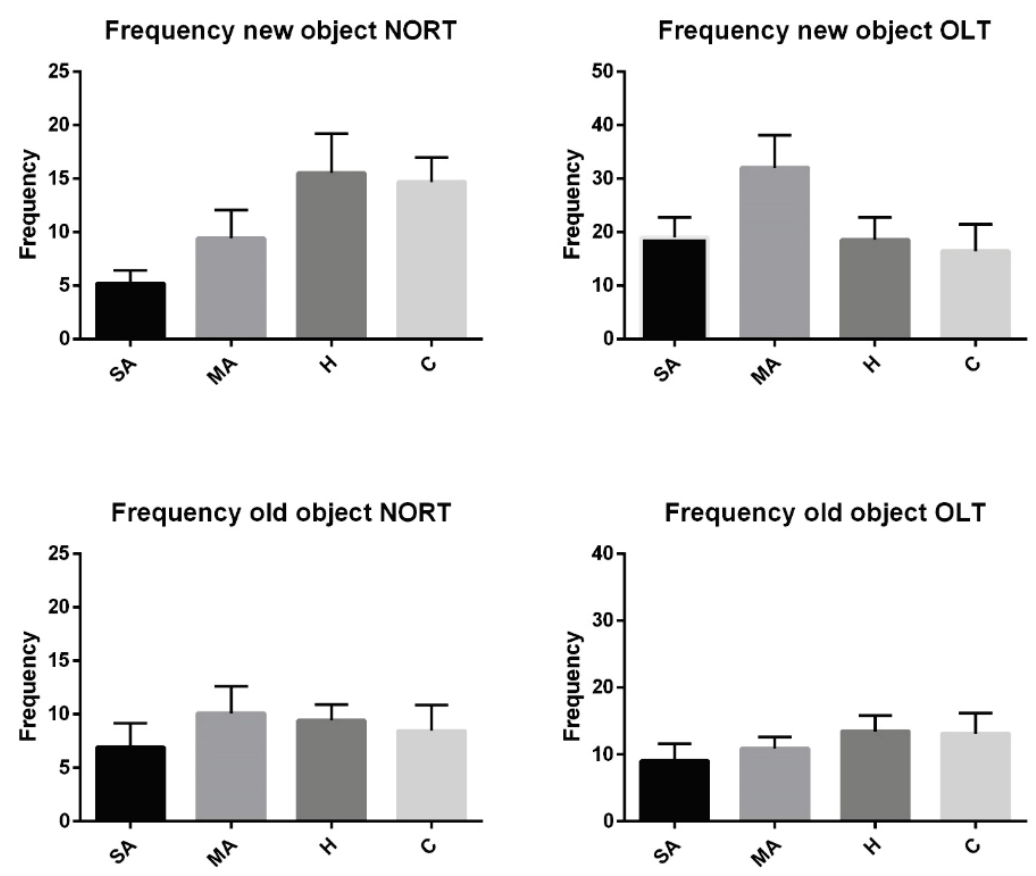

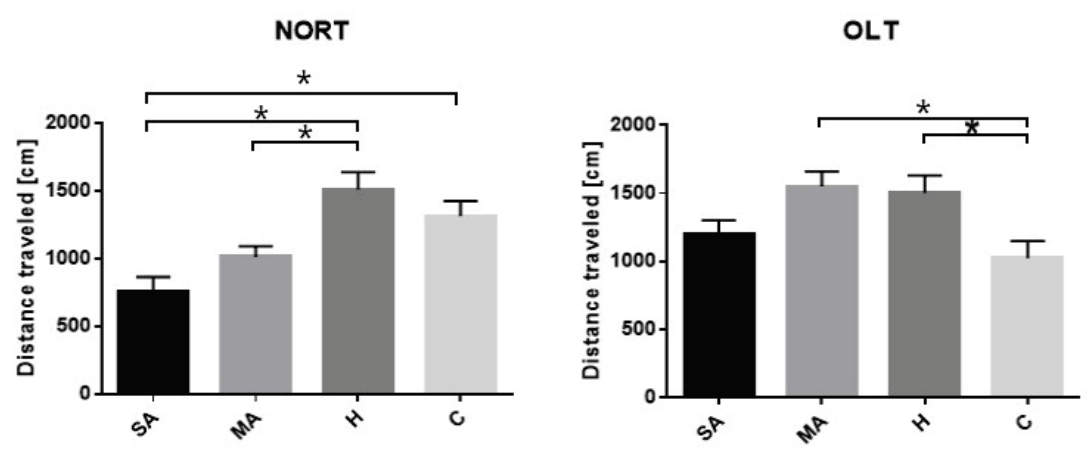

Fig. 2. The effect of prenatal $M A, S A$, Hypoxia, and Control on behavior in the NORT and OLT test. $M A=$ methamphetamine; $\quad S A=$ saline; $\mathrm{H}=$ hypoxia; $\mathrm{C}=$ control. Values are mean \pm SEM $(n=9-10), * p<0.01$.
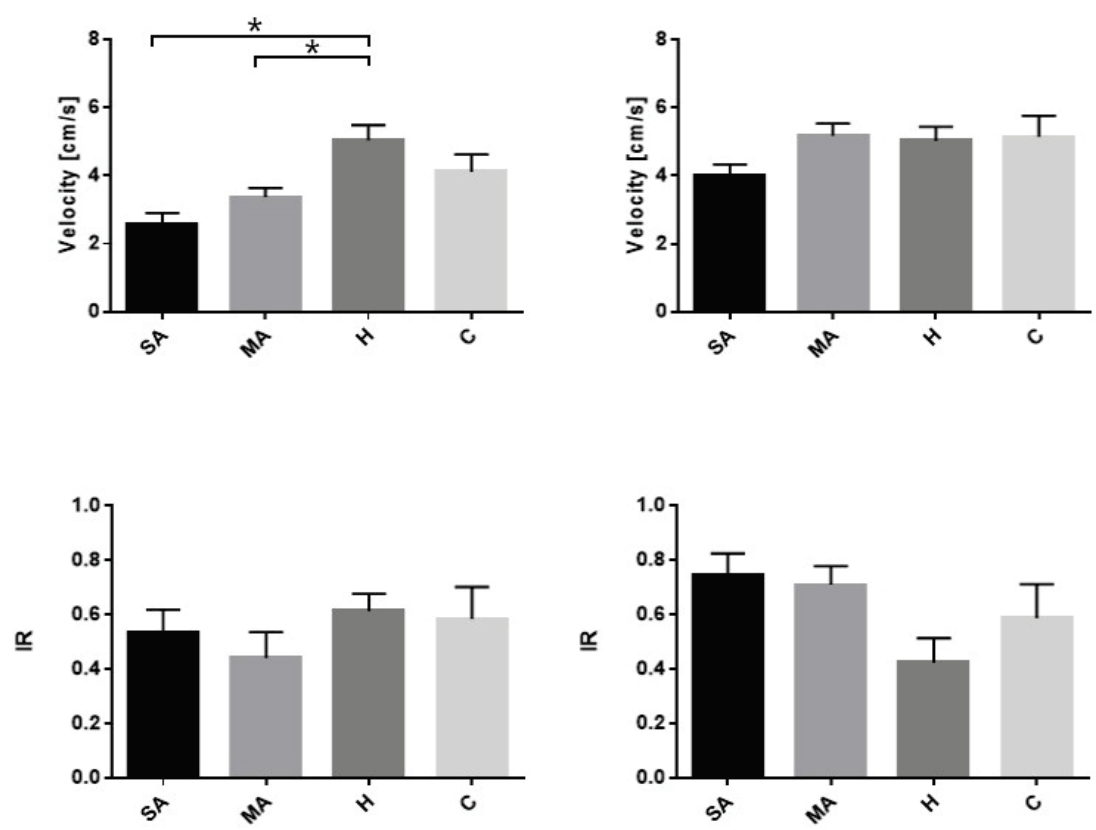

\section{Discussion}

The goal of the present study was to find a novel animal experimental model for ADHD since our previous studies have shown memory recognition impairment in adults after prenatal MA exposure (Fialová et al. 2015) and increased locomotor activity in adolescents and adults (Ochozková et al. 2019). We used NORT to test working and OLT to test spatial memory. Both tests are commonly used in Wistar rats strain (Swartzwelder et al. 2012, Moreton et al. 2019).

Surprisingly, the data from this study did not find any significant differences in the investigation ratios between groups relative to NORT and OLT, which means no memory impairment, was detected in adolescents after prenatal MA exposure or after prenatal hypoxia on these types of cognition tests. In summary, (1) hypoxia-induced significant differences in distance traveled and velocity on the NORT compared to controls, as well as the salineand MA-exposed groups, and (2) greater distance traveled was observe on the OLT in the hypoxia and MA exposed groups relative to controls.

These findings support those seen in previous studies. Rats exposed to prenatal hypoxia showed behavior changes during the open-field test (Hermans et al. 1992, Sab et al. 2013). Different types of hyperactivity were described; rats had spontaneous exploratory and motor hyperactivity during the open field test and short-term memory deficits relative to object recognition in adulthood after prenatal hypoxia on day GD 17. In the same study, they also found that prenatal hypoxia caused white matter damage to the corpus callosum and brainstem, but not in the motor cortex (Delcour et al. 2012). Hyperactivity during the open field test was also observed in newborn (P15) rats exposed to prenatal hypoxia (Cai et al. 1999). Interestingly, another study showed that prenatal hypoxia leads to hyperactivity during the open field test during postnatal development. However, in adulthood, rats had a greater tendency to "freeze", and overall locomotor activity was reduced (Dubrovický et al. 2014). Rats exposed to prenatal hypoxia had delayed nerve cell maturation and increased 
neurodegeneration in the cortex and striatum, although these structural changes were no longer apparent in adulthood (Dubrovskaya and Zhuravin 2010). In humans, prenatal hypoxia may result in disturbances in central dopaminergic systems that persist in adulthood (Plomp et al. 2009). It was also found that prenatal hypoxia may cause selective vulnerability of mesencephalic dopaminergic neurons and affect noradrenergic neurons in the locus coeruleus via immunoreactivity of tyrosine hydroxylase, an enzyme that limits catecholamine synthesis. Both these effects are likely to predispose survivors of prenatal hypoxia to psychiatric or neurological disorders in adulthood (Pagida et al. 2016). Dysregulation of dopaminergic neurotransmission plays a significant role in the pathophysiology of several neurological disorders, including ADHD (Pagida et al. 2013).

Because no memory impairment was detected, our present study is at odds with our previous findings (Fialová et al. 2015). Adolescent rats were used in the present study, while adult animals were used in the earlier study (Fialová et al. 2015); the maturation of the hippocampus may explain some or all of the discrepancies. On the other hand, the greater motor activity (distance traveled) observed in the OLT experiment involving MA exposed animals was consistent with that seen in our previous studies and the studies of others (Diaz et al. 2014). Prenatal MA exposure resulted in increased locomotor activity (i.e. voluntary movement) and also increased locomotor activity in a novel environment (Ochozková et al. 2019).

The question of whether prenatal MA exposure can be considered a good animal model for ADHD remains unanswered. ADHD is a heterogeneous disorder with different behavioral symptoms that probably result from different combinations of genetic and environmental factors. The heterogeneity is often divided into hyperactivity and inattention. Animal models are characterized by a list of criteria, which include behavioral characteristics (e.g. impulsivity, hyperactivity, altered reinforcement of novel behavior and deficient extinction of previously reinforced behavior, and impaired learning and memory) together with neurobiological characteristics (Sagvolden et al. 2011). Interestingly, according to recent findings, hyperactivity may be a compensatory mechanism to produce more lactate in muscles and thereby supply the brain with energy (Medin et al. 2019).

The most relevant animal model of ADHD is spontaneously hypertensive rats (SHR), which exhibits all the behavioral and most of the neurobiological criteria. SHR have higher extracellular dopamine in the nucleus accumbens shell, and juvenile SHR have increased levels of dopamine in the striatum and prefrontal cortex, with upregulation of D1 receptors (DRD1) in the prefrontal cortex and hypofunction of D2 receptors or hyperexpression of the integral plasmalemmal protein of the dopamine transporter responsible for dopamine clearance (Viggiano et al. 2004, Russell 2007).

Our previous study found that prenatal MA exposure increased basal levels of dopamine in the nucleus accumbens in rats (Bubeníková-Valešová et al. 2009). A major function of dopaminergic transmission is to modulate fast, ionotropic synaptic transmission mediated by the neurotransmitter glutamate. SHR have decreased activation of DRD1 in the striatum, which leads to decreased facilitation of N-methyl-D-aspartate (NMDA) receptor function (Papa et al. 1998). We found that prenatal MA exposure leads to changes in the NMDA NR1 receptor subunits in the hippocampus (Šlamberová et al. 2014). We previously found that prenatal MA exposure impairs recognition memory in adult rats and impairs their ability to concentrate (Fialová et al. 2015). A study from 2009 found that no significant effects of prenatal MA exposure were detected regarding open field test behaviors (Schutová et al. 2009). Collectively, our previous findings show that prenatal MA exposure has similar neurobiological characteristics to those seen in SHR. Hyperactivity alone is insufficient for the animal to qualify as ADHD model. Other characteristics have to be considered (Sagvolden et al. 2011).

In conclusion, our data showed no memory impairment after prenatal MA exposure or prenatal hypoxia; while prenatal hypoxia led to greater motor activity and velocity in rats on the NORT and OLT, while prenatal MA exposure only led to greater motor activity and velocity on the OLT.

This present study was conducted to better understand the effects of prenatal MA exposure on spatial and recognition memory of rats relative to prenatal hypoxia exposure and determine if prenatal MA exposure could be used as a valid model of ADHD. We are aware of the fact, that this current data are not sufficient to confirm or refute our hypothesis. Because our previous results (Ochozková et al. 2019) demonstrated that prenatal MA exposure induces hyperactivity, another symptom of the ADHD, more studies are necessary to 
test possible use of prenatal MA exposure as an animal model of the ADHD.

\section{Conflict of Interest}

There is no conflict of interest.

\section{Acknowledgements}

This work was supported by research program Progres Q 35, GAUK 1520218, GACR 18-03806S, and $260533 / \mathrm{SVV} / 2021$. This work was further supported by the ERDF/ESF project "PharmaBrain" CZ.02.1.01/0.0/0.0/16_025/0007444 funded from OP VVV. The authors express their appreciation to Thomas Secrest, for editing of the manuscript.

\section{References}

ABAR B, LAGASSE LL, WOULDES T, DERAUF C, NEWMAN E, SHAH R, LESTER BM: Cross-national comparison of prenatal methamphetamine exposure on infant and early child physical growth: A natural experiment. Prev Sci 15: 767-776, 2014. https://doi.org/10.1007/s11121-013-0431-5

ACUFF-SMITH KD, SCHILLING MA, FISHER JE, VORHEES CV: Stage-specific effects of prenatal d-methamphetamine exposure on behavioral and eye development in rats. Neurotoxicol Teratol 18: 199-215, 1996. https://doi.org/10.1016/0892-0362(95)02015-2

ASHERSON P: ADHD across the lifespan. Medicine 40: 623-627, 2012. https://doi.org/10.1016/j.mpmed.2012.08.007

ATALAR EG, UZBAY T, KARAKAŞ S: Modeling symptoms of attention-deficit hyperactivity disorder in a rat model of fetal alcohol syndrome. Alcohol Alcohol 51: 684-690, 2016. https://doi.org/10.1093/alcalc/agw019

BUBENÍKOVA-VALEŠOVÁ V, KAČER P, SYSLOVÁ K, RAMBOUSEK L, JANOVSKÝ M, SCHUTOVÁ B, HRUBÁ L, SLLAMBEROVÁ R: Prenatal methamphetamine exposure affects the mesolimbic dopaminergic system and behavior in adult offspring. Int J Dev Neurosci 27: 525-530, 2009. https://doi.org/10.1016/j.ijdevneu.2009.06.012

BUSH PG, MAYHEW TM, ABRAMOVICH DR, AGGETT PJ, BURKE MD, PAGE KR: Maternal cigarette smoking and oxygen diffusion across the placenta. Placenta 21: 824-833, 2000. https://doi.org/10.1053/plac.2000.0571

CAI Z, XIAO F, LEE B, PAUL IA, RHODES PG: Prenatal hypoxia-ischemia alters expression and activity of nitric oxide synthase in the young rat brain and causes learning deficits. Brain Res Bull 49: 359-365, 1999. https://doi.org/10.1016/S0361-9230(99)00076-3

CHANG L, SMITH LM, LOPRESTI C, YONEKURA ML, KUO J, WALOT I, ERNST T: Smaller subcortical volumes and cognitive deficits in children with prenatal methamphetamine exposure. Psychiatry Res 132: 95-106, 2004. https://doi.org/10.1016/j.pscychresns.2004.06.004

DELCOUR M, RUSSIER M, AMIN M, BAUD O, PABAN V, BARBE MF, COQ JO: Impact of prenatal ischemia on behavior, cognitive abilities and neuroanatomy in adult rats with white matter damage. Behav Brain Res 232: 233-244, 2012. https://doi.org/10.1016/j.bbr.2012.03.029

DIAZ SD, SMITH LM, LAGASSE LL, DERAUF C, NEWMAN E, SHAH R, LESTER BM: Effects of prenatal methamphetamine exposure on behavioral and cognitive findings at 7.5 years of age. J Pediatr 164: 1333-1338, 2014. https://doi.org/10.1016/j.jpeds.2014.01.053

DUBROVSKAYA NM, ZHURAVIN IA: Ontogenetic characteristics of behavior in rats subjected to hypoxia on day 14 or day 18 of embryogenesis. Neurosci Behav Physiol 40: 231-238, 2010. https://doi.org/10.1007/s11055-0099235-2

ENNACEUR A, NEAVE N, AGGLETON JP: Spontaneous object recognition and object location memory in rats: The effects of lesions in the cingulate cortices, the medial prefrontal cortex, the cingulum bundle and the fornix. Exp Brain Res 113: 509-519, 1997. https://doi.org/10.1007/PL00005603

FIALOVÁ M, ŠÍROVÁ J, BUBENÍKOVÁ-VALEŠOVÁ V, ŠLAMBEROVÁ R: The effect of prenatal methamphetamine exposure on recognition memory in adult rats. Prague Med Rep 116: 31-39, 2015. https://doi.org/10.14712/23362936.2015.43

FUJÁKOVÁ-LIPSKI M, KAPING D, ŠÍROVÁ J, HORÁČEK J, PÁLENÍČEK T, ZACH P, ŠLAMBEROVÁ R: Trans-generational neurochemical modulation of methamphetamine in the adult brain of the Wistar rat. Arch Toxicol 91: 3373-3384, 2017. https://doi.org/10.1007/s00204-017-1969-y 
GETAHUN D, RHOADS GG, DEMISSIE K, LU SE, QUINN VP, FASSETT MJ, JACOBSEN SJ: In utero exposure to ischemichypoxic conditions and attention-deficit/hyperactivity disorder. Pediatrics 131: e53-e61, 2013. https://doi.org/10.1542/peds.2012-1298

GIBSON MAS, BUTTERS NS, REYNOLDS J, BRIEN JF: Effects of chronic prenatal ethanol exposure on locomotor activity, and hippocampal weight, neurons, and nitric oxide synthase activity of the young postnatal guinea pig. Neurotoxicol Teratol 22: 183-192, 2000. https://doi.org/10.1016/S0892-0362(99)00074-4

GILBERTSON RJ, BARRON S: Neonatal ethanol and nicotine exposure causes locomotor activity changes in preweanling animals. Pharmacol Biochem Behav 81: 54-64, 2005. https://doi.org/10.1016/j.pbb.2005.02.002

GOLAN H, HULEIHEL M: The effect of prenatal hypoxia on brain development: short-and long-term consequences demonstrated in rodent models. Dev Sci 9: 338-349, 2006. https://doi.org/10.1111/j.1467-7687.2006.00498.x

HALPIN LE, COLLINS SA, YAMAMOTO BK: Neurotoxicity of methamphetamine and 3,4-methylenedioxymethamphetamine. Life Sci 97: 37-44, 2014 https://doi.org/10.1016/j.1fs.2013.07.014

HOLUBOVÁ A, ŠTOFKOVÁ A, JURČOVIČOVÁ J, ŠLAMBEROVÁ R: The effect of neonatal maternal stress on plasma levels of adrenocorticotropic hormone, corticosterone, leptin, and ghrelin in adult male rats exposed to acute heterotypic stressor. Physiol Res 65 (Suppl 5): S557-S566, 2016. https://doi.org/10.33549/physiolres.933530

HERMANS R HM, HUNTER DE, MCGIVERN RF, CAIN CD, LONGO LD: Behavioral sequelae in young rats of acute intermittent antenatal hypoxia. Neurotoxicol Teratol 14: 119-129, 1992. https://doi.org/10.1016/0892$\underline{0362(92) 90060-\mathrm{N}}$

KNOPIK VS: Commentary: Smoking during pregnancy-genes and environment weigh in. Int J Epidemiol 39: 1203-1205, 2010. https://doi.org/10.1093/ije/dyq125

KNOPIK VS: Maternal smoking during pregnancy and child outcomes: real or spurious effect? Dev Neuropsychol 34: 1-36, 2009. https://doi.org/10.1080/87565640802564366

KWIATKOWSKI MA, ROOS A, STEIN DJ, THOMAS KG, DONALD K: Effects of prenatal methamphetamine exposure: A review of cognitive and neuroimaging studies. Metab Brain Dis 29: 245-254, 2014. https://doi.org/10.1007/s11011-013-9470-7

MARESOVA D, VALKOUNOVÁ I, JANDOVÁ K, BORTELOVA J, TROJAN S: Excitability changes of cortical neurons during the postnatal period in rats exposed to prenatal hypobaric hypoxia. Physiol Res 50: 215-219, 2001.

MEDIN T, MEDIN H, HEFTE MB, STORM-MATHISEN J, BERGERSEN LH: Upregulation of the lactate transporter monocarboxylate transporter 1 at the blood-brain barrier in a rat model of attention-deficit/hyperactivity disorder suggests hyperactivity could be a form of self-treatment. Behav Brain Res 360: 279-285, 2019. https://doi.org/10.1016/j.bbr.2018.12.023

MORETON E, BARON P, TIPLADY S, MCCALL S, CLIFFORD B, LANGLEY-EVANS SC, VOIGT JP: Impact of early exposure to a cafeteria diet on prefrontal cortex monoamines and novel object recognition in adolescent rats. Behav Brain Res 363: 191-198, 2019. https://doi.org/10.1016/j.bbr.2019.02.003

OCHOZKOVÁ A, MIHALČÍKOVÁ L, YAMAMOTOVÁ A, ŠLAMBEROVÁ R: ADHD symptoms induced by prenatal $\begin{array}{lllllll}\text { methamphetamine } & \text { exposure. } & \text { Physiol } & \text { Res } & 68 & \text { (Suppl } & 3 \text { ): }\end{array}$ https://doi.org/10.33549/physiolres.934358

OORSCHOT DE, VOSS L, COVEY MV, BILKEY DK, SAUNDERS SE: ADHD-like hyperactivity, with no attention deficit, in adult rats after repeated hypoxia during the equivalent of extreme prematurity. J Neurosci Methods 166: 315-322, 2007. https://doi.org/10.1016/j.jneumeth.2007.01.010

PAGIDA MA, KONSTANTINIDOU AE, TSEKOURA E, MANGOURA D, PATSOURIS E, PANAYOTACOPOULOU MT: Vulnerability of the mesencephalic dopaminergic neurons of the human neonate to prolonged perinatal hypoxia: an immunohistochemical study of tyrosine hydroxylase expression in autopsy material. J Neuropathol Exp Neurol 72: 2013. https://doi.org/10.1097/NEN.0b013e31828b48b3

PAGIDA MA, KONSTANTINIDOU AE, KORELIDOU A, KATSIKA D, TSEKOURA E, PATSOURIS E, PANAYOTACOPOULOU MT: The effect of perinatal hypoxic/ischemic injury on tyrosine hydroxylase expression in the locus coeruleus of the human neonate. Dev Neurosci 38: 41-53, 2016. https://doi.org/10.1159/000439270 
PAPA M, SERGEANT JA, SADILE AG: Reduced transduction mechanisms in the anterior accumbal interface of an animal model of attention-deficit hyperactivity disorder. Behav Brain Res 94: 187-195, 1998. https://doi.org/10.1016/S0166-4328(97)00179-4

PLOMP E, VAN ENGELAND H, DURSTON S: Understanding genes, environment and their interaction in attentiondeficit hyperactivity disorder: is there a role for neuroimaging? Neuroscience 164: 230-240, 2009. https://doi.org/10.1016/j.neuroscience.2009.07.024

ROBINSON S, CORBETT CJ, WINER JL, CHAN LA, MAXWELL JR, ANSTINE CV, JANTZIE LL: Neonatal erythropoietin mitigates impaired gait, social interaction and diffusion tensor imaging abnormalities in a rat model of prenatal brain injury. Exp Neurol 302: 1-13, 2018. https://doi.org/10.1016/j.expneurol.2017.12.010

RUSSELL VA: Neurobiology of animal models of attention-deficit hyperactivity disorder. J Neurosci Methods 161: 185-198, 2007. https://doi.org/10.1016/j.jneumeth.2006.12.005

SAB IM, FERRAZ MMD, AMARAL TAS, RESENDE AC, FERRAZ MR, MATSUURA C, MENDES-RIBEIRO AC: Prenatal hypoxia, habituation memory and oxidative stress. Pharmacol Biochem Behav 107: 24-28, 2013. https://doi.org/10.1016/j.pbb.2013.04.004

SAGVOLDEN T, JOHANSEN EB, AASE H, RUSSELL VA: A dynamic developmental theory of attentiondeficit/hyperactivity disorder (ADHD) predominantly hyperactive/impulsive and combined subtypes. Behav Brain Sci 28: 397-418, 2005. https://doi.org/10.1017/S0140525X05000075

SAGVOLDEN T, JOHANSEN EB: Rat models of ADHD. In: Behavioral Neuroscience of Attention Deficit Hyperactivity Disorder and its Treatment. STANFORD C, TANNOCK R (eds), Springer, Berlin, Heidelberg, 2011, pp 301-315. https://doi.org/10.1007/7854_2011_126

SCHUTOVÁ B, HRUBÁ L, POMETLOVÁ M, DEYKUN K, ŠLAMBEROVÁ R: Cognitive functions and drug sensitivity in adult male rats prenatally exposed to methamphetamine. Physiol Res 58: 741-750, 2009. https://doi.org/10.33549/physiolres.931562

SWARTZWELDER NA, RISHER ML, ABDELWAHAB SH, D'ABO A, REZVANI AH, LEVIN ED, ACHESON SK: Effects of ethanol, $\Delta 9$-tetrahydrocannabinol, or their combination on object recognition memory and object preference in adolescent and adult male rats. Neurosci Lett 527: 11-15, 2012. https://doi.org/10.1016/j.neulet.2012.08.037

ŠLAMBEROVÁ R, POMETLOVÁ M, CHAROUSOVÁ P: Postnatal development of rat pups is altered by prenatal methamphetamine exposure. Prog Neuropsychopharmacol Biol Psychiatry 30: 82-88, 2006. https://doi.org/10.1016/j.pnpbp.2005.06.006

ŠLAMBEROVÁ R: Drugs in pregnancy: the effects on mother and her progeny. Physiol Res 61 (Suppl 1): S123-S135, 2012. https://doi.org/10.33549/physiolres. 932357

ŠLAMBEROVÁ R, VRAJOVÁ M, SCHUTOVÁ B, MERTLOVÁ M, MACÚCHOVÁ E, NOHEJLOVÁ K, YAMAMOTOVÁ A: Prenatal methamphetamine exposure induces long-lasting alterations in memory and development of NMDA receptors in the hippocampus. Physiol Res 63 (Suppl 4): S547-S558. 2014. https://doi.org/10.33549/physiolres.932926

TIESLER CM, HEINRICH J: Prenatal nicotine exposure and child behavioural problems. Eur Child Adolesc Psychiatry 23: 913-929, 2014. https://doi.org/10.1007/s00787-014-0615-y

VAVRINKOVA B, BINDER T, VITKOVA I, ZIVNÝ J: Placental and umbilical cord changes in drug-addicted women. (Article in Czech) Ceska Gynekol 66: 345-349, 2001.

VETROVOY O, STRATILOV V, NIMIRITSKY P, MAKAREVICH P, TYULKOVA E: Prenatal hypoxia induces premature aging accompanied by impaired function of the glutamatergic system in rat hippocampus. Neurochem Res 46: 1-14, 2021. https://doi.org/10.1007/s11064-020-03191-z

VIGGIANO D, VALLONE D, SADILE A. Dysfunctions in dopamine systems and ADHD: evidence from animals and modeling. Neural Plast 11: 97-114, 2004. https://doi.org/10.1155/NP.2004.97

WAGNER GC, RICAURTE GA, SEIDEN LS, SCHUSTER CR, MILLER RJ, WESTLEY J: Long-lasting depletions of striatal dopamine and loss of dopamine uptake sites following repeated administration of methamphetamine. Brain Res 181: 151-160, 1980. https://doi.org/10.1016/0006-8993(80)91265-2 
WEI B, LI L, HE A, ZHANG Y, SUN M, XU Z: Hippocampal NMDAR-Wnt-Catenin signaling disrupted with cognitive deficits in adolescent offspring exposed to prenatal hypoxia. Brain Res 163: 157-164, 2016. https://doi.org/10.1016/j.brainres.2015.11.041

ZHU JP, XU W, ANGULO N, ANGULO JA: Methamphetamine-induced striatal apoptosis in the mouse brain: comparison of a binge to an acute bolus drug administration. Neurotoxicology 27: 131-136, 2006. https://doi.org/10.1016/j.neuro.2005.05.014

ZHU JL, OLSEN J, LIEW Z, LI J, NICLASEN J, OBEL C: Parental smoking during pregnancy and ADHD in children: the Danish national birth cohort. Pediatrics 134: 382-388, 2014. https://doi.org/10.1542/peds.2014-0213

ZHURAVIN IA, DUBROVSKAYA NM, VASILEV DS, POSTNIKOVA TY, ZAITSEV AV: Prenatal hypoxia produces memory deficits associated with impairment of long-term synaptic plasticity in young rats. Neurobiol Learn Mem 164: 107066, 2019. https://doi.org/10.1016/j.nlm.2019.107066 